\title{
Clausena anisata-mediated protection against lipopolysaccharide-induced acute lung injury in mice
}

\author{
CHAN-MI JEON $^{1,2}$, IN-SIK SHIN ${ }^{1,3}$, NA-RAE SHIN ${ }^{1}$, JU-MI HONG ${ }^{1}$, OK-KYOUNG KWON ${ }^{1}$, JUNG-HEE KIM ${ }^{1}$, \\ SEI-RYANG OH ${ }^{1}$, TRAN-THE BACH ${ }^{4}$, DO-VAN HAI ${ }^{4}$, BUI-HONG QUANG ${ }^{4}$, SANG-HO CHOI $^{5}$, \\ JOONGKU LEE ${ }^{5,6}$, PYUNG-KEUN MYUNG ${ }^{2}$ and KYUNG-SEOP AHN ${ }^{1}$
}

\author{
${ }^{1}$ Natural Medicine Research Center, Korea Research Institute of Bioscience and Biotechnology, Cheongwon-gu, \\ Cheongju-si, Chungcheongbuk-do 28116; ${ }^{2}$ College of Pharmacy, Chungnam National University, Yuseong-gu, Daejeon, \\ Chungcheongnam-do 34134; ${ }^{3}$ College of Veterinary Medicine, Chonnam National University, Buk-gu, Gwangju 500-757, \\ Republic of Korea; ${ }^{4}$ IEBR, Vietnam Academy of Science and Technology (VAST), Cay Giay, Ha Noi, Vietnam; \\ ${ }^{5}$ International Biological Material Research Center, Korea Research Institute of Bioscience and Biotechnology, \\ Yuseong-gu, Daejeon 34141; ${ }^{6}$ Department of Environment and Forest Resources, \\ Chungnam National University, Daejeon 34134, Republic of Korea
}

Received February 11, 2015; Accepted February 26, 2016

DOI: $10.3892 /$ ijmm.2016.2515

\begin{abstract}
Clausena anisata (Willd.) Hook.f. ex Benth. (CA), which is widely used in traditional medicine, reportedly exerts antitumor, anti-inflammatory and other important therapeutic effects. The aim of the present study was to investigate the potential therapeutic effects of CA in a mouse model of lipopolysaccharide (LPS)-induced acute lung injury (ALI) and in LPS-stimulated RAW 264.7 cells. Male C57BL/6 mice were administered treatments for 3 days by oral gavage. On day 3, the mice were instilled intranasally with LPS or PBS followed $3 \mathrm{~h}$ later by oral CA $(30 \mathrm{mg} / \mathrm{kg})$ or vehicle administration. In vitro, CA decreased nitric oxide (NO) production and pro-inflammatory cytokines, such as interleukin (IL)-6 and prostaglandin E2 ( $\left.\mathrm{PGE}_{2}\right)$, in LPS-stimulated RAW 264.7 cells. CA also reduced the expression of pro-inflammatory mediators, such as cyclooxygenase- 2 . In vivo, $\mathrm{CA}$ administration significantly reduced inflammatory cell numbers in the bronchoalveolar lavage fluid (BALF) and suppressed pro-inflammatory cytokine levels, including tumor necrosis factor- $\alpha$ (TNF- $\alpha$ ), IL-6, and IL-1 $\beta$, as well as reactive oxygen species production in the BALF. $\mathrm{CA}$ also effectively reduced airway inflammation in mouse
\end{abstract}

Correspondence to: Dr Kyung Seop Ahn, Natural Medicine Research Center, Korea Research Institute of Bioscience and Biotechnology, 30 Yeongudanji-ro, Ochang-eup, Cheongwon-gun, Cheongju-si, Chungcheongbuk-do 28116, Republic of Korea E-mail:ksahn@kribb.re.kr

Professor Pyung-Keun Myung, College of Pharmacy, Chungnam National University, 99 Daehak-ro, Yuseong-gu, Daejeon, Chungcheongnam-do 34134, Republic of Korea

E-mail: pyung@cnu.ac.kr

Key words: Clausena anisata (Willd.) Hook.f. ex Benth., acute lung injury, lipopolysaccharide, inflammation, nuclear factor- $\mathrm{kB}$ lung tissue of an LPS-induced ALI mouse model, in addition to decreasing inhibitor $\kappa \mathrm{B}(\mathrm{I} \kappa \mathrm{B})$ and nuclear factor- $\kappa \mathrm{B}(\mathrm{NF}-\kappa \mathrm{B})$ p65 phosphorylation. Taken together, the findings demonstrated that CA inhibited inflammatory responses in a mouse model of LPS-induced ALI and in LPS-stimulated RAW 264.7 cells. Thus, CA is a potential candidate for development as an adjunctive treatment for inflammatory disorders, such as ALI.

\section{Introduction}

Acute lung injury (ALI) is the basis of acute respiratory distress syndrome (ARDS) and is involved in the development of multiple organ failure, which leads to death in patients with sepsis, shock and pneumonia (1-3). ALI is characterized by neutrophil accumulation in the lung, lung tissue destruction, lung edema and diffuse lung inflammation, which is accompanied by the overexpression of inflammatory mediators, including cytokines and chemokines $(4,5)$. The search for an effective ALI therapy has been ongoing for decades $(6,7)$. However, there are few effective therapies for ALI (8). Therefore, it is essential to develop novel effective therapies for ALI.

Lipopolysaccharide (LPS), a constituent of the outer membrane of gram-negative bacteria, is a key pathogen in animal models of ALI $(9,10)$. Previous studies have reported that LPS induces direct/indirect neutrophil and macrophage activation, resulting in the release of pro-inflammatory mediators $(11,12)$. This cascade eventually aggravates inflammatory responses on various lesions that have been damaged by stimuli.

Previous findings have demonstrated that LPS exerts its inflammatory responses by activating specific inflammatory signaling pathways, such as the nuclear factor- $\kappa \mathrm{B}(\mathrm{NF}-\kappa \mathrm{B})$ signaling pathway. $\mathrm{NF}-\kappa \mathrm{B}$, a central regulator of inflammation, and the NF- $\kappa \mathrm{B}$ signaling pathway are considered to be involved in the pathogenesis of ALI (12). Once NF- $\kappa$ B is activated, NF- $\kappa B$ signaling proceeds through phosphorylation and the subsequent phosphorylation and degradation of the inhibitor of $\kappa \mathrm{B}(\mathrm{I} \kappa \mathrm{B})$, 
resulting in the cytoplasmic release and nuclear translocation of $\mathrm{NF}-\kappa \mathrm{B}(13,14)$. Thus, NF- $\kappa \mathrm{B}$ activation induces the transcription of pro-inflammatory mediators. These mediators include tumor necrosis factor- $\alpha$ (TNF- $\alpha$ ), interleukin (IL)-1 $\beta$, IL-6, cyclooxygenase-2 (COX-2) and prostaglandin E2 ( $\left.\mathrm{PGE}_{2}\right)(15-18)$, which play critical roles in ALI (12). Thus, $N F-\kappa B$ is a potential therapeutic target in ALI.

Clausena anisata (Willd.) Hook.f. ex Benth. (CA), locally known as 'isifudu' in the South African isiZulu language, is widely used in traditional medicine to treat many diseases. Various parts of CA, such as leaves, roots and bark, are reportedly useful as effective remedies against parasitic infections, eye complaints, heart disorders, hypertension, constipation, gastroenteritis, malaria, other febrile conditions, other inflammatory conditions, toothaches, swollen gums, mental disorders, impotence and sterility (19-25).

However, the anti-inflammatory effect of CA has yet to be studied in ALI. Thus, the present study aimed to evaluated the effects of CA, and to elucidate the underlying mechanisms of action of CA, in a mouse model of LPS-induced ALI and in LPS-stimulated RAW 264.7 cells.

\section{Materials and methods}

Preparation of plant extract. Clausena anisata (Willd.) Hook.f. ex Benth. of the family Rutaceae was collected from Ninh Thuan province, Thuan Bac district, Cong Hai, Vietnam. Plant samples were identified by Tran-The Bach, Institute of Ecology and Biological Resources. Voucher specimens (KRIB 0034836,7,8) have been deposited in the herbarium (KRIB) of the Korea Research Institute of Bioscience and Biotechnology (KRIBB). After grinding the twigs and leaves of CA, the powder $(220 \mathrm{~g})$ was treated with $\mathrm{MeOH}$ and sonicated several times at room temperature for 3 days to produce an extract (8.61 g). CA extract was dissolved in DMSO and stored at $-20^{\circ} \mathrm{C}$.

\section{In vitro experiment}

Cell culture. RAW 264.7 macrophages were maintained at $1 \times 10^{5}$ cells $/ \mathrm{ml}$ in Dulbecco's modified Eagle's medium (DMEM) supplemented with $10 \%$ heat-inactivated fetal bovine serum (FBS) (both from Sigma-Aldrich, St. Louis, MO, USA) and 1\% (w/v) antibiotic-antimycotic solution (Invitrogen, Grand Island, NY, USA) in a $95 \%$ air and $5 \% \mathrm{CO}_{2}$ humidified atmosphere at $37^{\circ} \mathrm{C}$. The cells were seeded in 96-well plates at $5 \times 10^{4}$ cells/well and incubated in serum-free medium in the presence of different CA concentrations $(5,10,20$ and $40 \mu \mathrm{g} / \mathrm{ml})$. CA was obtained from the Plant Extract Bank at the Korea Research Institute of Bioscience and Biotechnology (KRIBB) (BVN12106; Daejeon, Korea).

Cell viability assay. Cell viability was evaluated by determining the mitochondrial reductase function using with an assay based on the reduction of tetrazolium salt 3-(4,5-dimethylthiazol-2-yl)-2,5-diphenyltetrazolium bromide (MTT) (CAS\#298-93-1; Amresco, LLC, Solon, OH, USA) into formazan crystals. Formazan formation is proportional to the number of functional mitochondria in living cells. To determine cell viability, $50 \mathrm{mg} / \mathrm{ml}$ of MTT was added to $5 \mu \mathrm{l}$ of cell suspension (1x10 cells/ $\mathrm{ml}$ in 96 -well plates) for $4 \mathrm{~h}$. The formazan formed was dissolved in acidic 2-propanol, and the optical density was measured at $570 \mathrm{~nm}$ using a microplate reader (Benchmark; Bio-Rad Laboratories, Inc., Hercules, CA, USA). The optical density of formazan formed in the control (untreated) cells was set to $100 \%$ viability.

Measurement of nitric oxide (NO) production. NO production in RAW 264.7 cell culture supernatants was determined using the Griess reaction. The cells were incubated in the presence of LPS $(0.5 \mu \mathrm{g} / \mathrm{ml})$ at $37^{\circ} \mathrm{C}$ for $24 \mathrm{~h}$. The cells were then dispensed into 96-well plates, and $100 \mu \mathrm{l}$ of each supernatant was mixed with the same volume of Griess reagent (1\% sulfanilamide, $0.1 \% \mathrm{~N}$-(1-naphathyl)-ethylenediamine dihydrochloride and 5\% phosphoric acid) and agitated gently for $10 \mathrm{~min}$ at room temperature. The nitrite concentration was measured at $540 \mathrm{~nm}$ using sodium nitrite to generate a standard curve.

Measurement of $\mathrm{PGE}_{2}$ and pro-inflammatory cytokine production. Cultures were serum-starved for $24 \mathrm{~h}$ and treated with experimental agents. Following culture incubation under experimental conditions, the media from each sample were collected and assessed for IL-6 synthesis using a commercial enzyme-linked immunosorbent assay (ELISA) (R\&D Systems, Inc., Minneapolis, MN, USA) according to the manufacturer's protocol, and the assay was calibrated spectrophotometrically with a standard curve. Supernatant $\mathrm{PGE}_{2}$ levels were determined using a $\mathrm{PGE}_{2}$ enzyme immuno assay (EIA) kit (Cayman Chemical Co., Ann Arbor, MI, USA) according to the manufacturer's protocol.

Reverse transcription-quantitative polymerase chain reaction $(R T-q P C R)$. Total RNA was reverse transcribed using AccuPower RT Premix (Bioneer Corporation, Daejeon, Korea) according to the manufacturer's instructions. The resulting cDNA (equivalent to $40 \mathrm{ng}$ total RNA) was used for

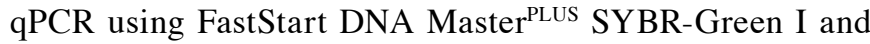
LightCycler (both from Roche Diagnostics, Indianapolis, IN, USA) according to the manufacturer's instructions. qPCR was performed using the primers: COX-2, sense, 5'-GAA GTC TTT GGT CTG GTC TCC TG-3' and antisense, 5'-GTC TGC TGG TTT GGA ATA GTT GC-3'; and $\beta$-actin sense, 5'-CGC TCA TTG CCG ATA GTG AT-3' and antisense 5'-TGT TTG AGA CCT TCA ACA CC-3'. All of the samples were normalized to $\beta$-actin. qPCR products were subjected to electrophoresis on $1.5 \%$ agarose gels and stained with ethidium bromide. Images were captured with an Olympus C4000 zoom camera system (Olympus America Inc., Melville, NY, USA).

Western blot analysis. Cells $\left(1 \times 10^{6}\right)$ were harvested and washed twice in cold Tris-buffered saline (TBS). The cells were solubilized in ice-cold $1 \%$ Triton X-100 lysis buffer. After $30 \mathrm{~min}$ on ice, the lysates were clarified by centrifugation at $600 \mathrm{x} \mathrm{g}$ for $20 \mathrm{~min}$. Proteins $(20 \mu \mathrm{g})$ were resolved by sodium dodecyl sulfate-polyacrylamide gel electrophoresis (SDS-PAGE) (10\% acrylamide) and transferred to nitrocellulose membranes. The membranes were incubated with blocking solution (5\% skim milk) and then incubated overnight at $4^{\circ} \mathrm{C}$ with the appropriate primary antibodies. The primary antibodies and dilutions used were: anti- $\beta$-actin (1:2,000 dilution; Cat. no. P60709; Cell Signaling Technology, Inc., Beverly, MA, USA) and anti-COX-2 (1:1,000 dilution; Cat. no. SC-1745; Santa Cruz Biotechnology, Inc., Santa Cruz, CA, USA). The membranes were washed three times with TBS containing Tween-20 (TBST) and then incubated with a 1:3,000 dilution of horseradish peroxidase (HRP)-conjugated secondary antibodies 
(Cat. no. SC-2027; Santa Cruz Biotechnology, Inc.) for $1 \mathrm{~h}$ at room temperature. The membranes were again washed three times with TBST and then developed using an enhanced chemiluminescence (ECL) kit (Thermo Fisher Scientific, Waltham, MA, USA). For quantitative analysis, densitometric band values were determined using ChemiDoc (Bio-Rad Laboratories, Inc.).

\section{In vivo experiment}

Animals. Male C57BL/6 mice (6-8 weeks of age) were obtained from Orient Co. (Seoul, Korea). The mice were provided with food and water ad libitum in an animal facility at a temperature of $22-24{ }^{\circ} \mathrm{C}$ and on a $12 \mathrm{~h}$ light/dark cycle under specific pathogen-free conditions. The mice were housed for a minimum of one week for environmental adaptation prior to experimentation. Experimental procedures were approved by the Institutional Animal Care and Use Committee of the Korea Research Institute of Bioscience and Biotechnology.

LPS-induced ALI in mice. Specific pathogen-free male $\mathrm{C} 57 \mathrm{BL} / 6$ mice were randomly divided into four groups $(\mathrm{n}=7 /$ group): i) NC (normal control); ii) LPS (LPS treatment); iii) Dex (LPS treatment + oral gavage of $5 \mathrm{mg} / \mathrm{kg}$ dexamethasone for 3 days); and iv) CA (LPS treatment + oral gavage of $30 \mathrm{mg} / \mathrm{kg} \mathrm{CA}$ for 3 days). The mice from the control and LPS groups received an equal volume of phosphate-buffered saline (PBS) instead of dexamethasone or CA. Three hours after drug administration on the third day, the mice were slightly anesthetized with diethyl ether inhalation, and $10 \mu \mathrm{g}$ of LPS in $50 \mu \mathrm{l}$ of PBS was instilled intranasally (i.n.) to induce lung injury. The mice in the control group were given $50 \mu \mathrm{l}$ of PBS without LPS. Twenty-four hours after the LPS treatment, the mice were sacrificed by an i.p. injection of pentobarbital $(50 \mathrm{mg} / \mathrm{kg}$; Hanlim Pharm. Co. Ltd., Seoul, Korea) and bronchoalveolar lavage fluid (BALF) and lung tissue samples were harvested for further studies.

BALF collection and cell counting. BALF collection was performed three times through a tracheal cannula with autoclaved PBS and instilled up to a total volume of $1.4 \mathrm{ml}$. The BALF was centrifuged at $200 \mathrm{x}$ g for $15 \mathrm{~min}$ at $4^{\circ} \mathrm{C}$. Following centrifugation, the supernatant was stored at $-70^{\circ} \mathrm{C}$ for subsequent cytokine assays. The total inflammatory cell numbers were assessed by counting cells in at least five squares of a hemocytometer after excluding dead cells by trypan blue staining. To determine differential cell counts, $100 \mu \mathrm{l}$ of BALF was centrifuged onto slides using a Cytospin (Hanil Science Industrial, Seoul, Korea). After the slides were dried, the cells were fixed and stained using Diff-Quik ${ }^{\circledR}$ staining reagent (B4132-1A; IMEB Inc., Deerfield, IL, USA).

Measurement of reactive oxygen species (ROS). Detection of cellular ROS in inflammatory cells was performed using 2',7'-dichlorofluorescein diacetate (DCF-DA) reagent as part of a kit purchased from Abcam (ab112851; Cambridge, MA, USA). After cell counting, $100 \mu \mathrm{l}$ of inflammatory cells were seeded in 96-well plates. The cells were stained with $20 \mu \mathrm{M}$ DCFDA for $30 \mathrm{~min}$ at $37^{\circ} \mathrm{C}$. Fluorescence intensity was then measured at $485 \mathrm{~nm}$ excitation and $530 \mathrm{~nm}$ emission using a microplate reader (Bio-Rad Laboratories, Inc.).

Measurement of cytokine levels in BALF. TNF- $\alpha, \mathrm{IL}-1 \beta$ and IL-6 levels in BALF were measured using ELISA kits (BioSource International, Camarillo, CA, USA). The procedures were performed according to the manufacturer's instructions.
Histopathological lung examination. After obtaining the BALF samples, lung tissue was fixed in $10 \%$ (v/v) neutral-buffered formalin. Lung tissues were embedded in paraffin, cut into $4-\mu \mathrm{m}$ sections, and stained with hematoxylin and eosin (H\&E) solution (both from Sigma-Aldrich; hematoxylin, MHS-16; eosin, HT110-1-32) to estimate inflammation.

Western blot analysis. Lung tissues were harvested and homogenized $(1 / 10 \mathrm{w} / \mathrm{v})$ using a homogenizer and tissue lysis/extraction reagent containing a protease inhibitor cocktail (both from Sigma-Aldrich). Protein concentrations were determined using a Bradford reagent (Bio-Rad Laboratories, Inc.,). Western blotting was performed as described above, and the following primary antibodies and dilutions used were: anti-IкB (1:1,000 dilution; Cell Signaling Technology, Inc.,), anti-NF-кB/ p65 (1:1,000 dilution; Santa Cruz Biotechnology, Inc.) and anti$\beta$-actin (1:2,000 dilution; Cell Signaling Technology, Inc.).

Images captured and photomicrography. The photomicrographs were obtained using a Photometric Quantix digital camera running Windows, and images were assembled in Adobe Photoshop 7.0. Images were cropped and corrected for brightness and contrast but were not otherwise manipulated.

Statistical analysis. Data were presented as the means \pm standard error of the mean (SEM). Statistical significance was determined using analysis of variance (ANOVA) followed by a multiple comparison test with Dunnett's adjustment. $\mathrm{P}<0.05$ was considered to indicate a statistically significant difference.

\section{Results}

In vitro evaluation

Effects of CA on NO production in LPS-stimulated RAW 264.7 cells. Non-toxic CA concentrations (5, 10, 20 and $40 \mu \mathrm{g} / \mathrm{ml}$ ) (Fig. 1A) were assessed for their ability to inhibit LPS-stimulated NO production. NO production was significantly increased in LPS-stimulated RAW 264.7 cells. By contrast, $\mathrm{CA}$ at 20 and $40 \mu \mathrm{g} / \mathrm{ml}$ induced a significant decrease in LPS-induced NO production; NO production decreased in a concentration-dependent manner (Fig. 1B).

Effect of $\mathrm{CA}$ on $\mathrm{PGE}_{2}$ and pro-inflammatory cytokine production in LPS-stimulated RAW 264.7 cells. $\mathrm{PGE}_{2}$ levels in the culture supernatant increased with LPS stimulation, and this effect was markedly reduced by $\mathrm{CA}$ treatment (Fig. 2A). Treatment of RAW 264.7 cells with LPS alone resulted in a significant increase in IL- 6 production compared with the control group (Fig. 2B). However, CA treatment significantly inhibited LPS induction of IL-6, in a dose-dependent manner.

Effect of CA on $m R N A$ and protein expression levels of inflammatory mediators. COX-2 mRNA and protein production was significantly increased in LPS-stimulated RAW 264.7 cells (Fig. 3). However, CA-treated cells exhibited significantly decreased COX-2 mRNA and protein levels compared with LPS-stimulated cells in a concentration-dependent manner.

\section{In vivo experiment}

Effect of CA on inflammatory cell counts in the BALF isolated from mice with LPS-induced ALI. The total number of inflammatory cells in the BALF comprised neutrophils, macrophages and lymphocytes. LPS challenge significantly increased the 

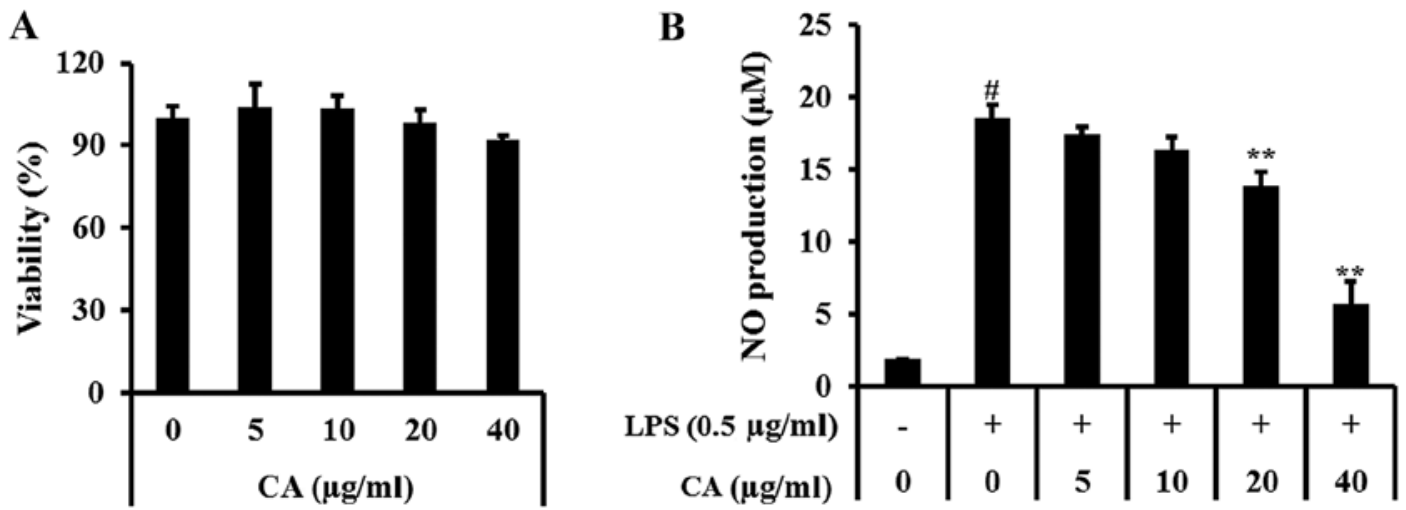

Figure 1. Effects of $C$. anisata (CA) on cell viability and the production of nitric oxide (NO) in lipopolysaccharide (LPS)-stimulated RAW 264.7 cells. The cells were treated with different concentrations $(5,10,20$ and $40 \mu \mathrm{g} / \mathrm{ml})$ of CA for $1 \mathrm{~h}$, and then incubated in the presence of LPS $(0.5 \mu \mathrm{g} / \mathrm{ml})$ for $24 \mathrm{~h}$. (A) Cell viability, (B) NO production. Significantly different from the control, ${ }^{*} \mathrm{P}<0.05$; significantly different from the cells treated with LPS alone, ${ }^{*} \mathrm{P}<0.05$; significantly different from the cells treated with LPS alone, ${ }^{* *} \mathrm{P}<0.01$.
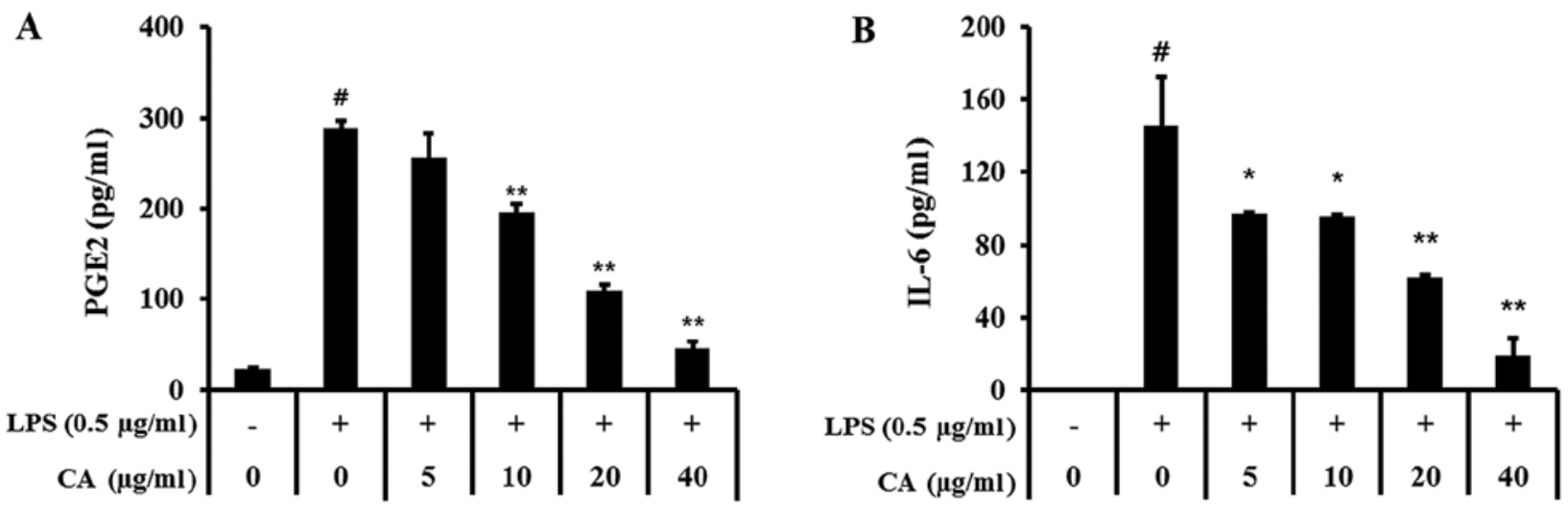

Figure 2. C. anisata (CA) reduces production of prostaglandin E2 (PGE2) and a pro-inflammatory cytokine in lipopolysaccharide (LPS)-stimulated RAW 264.7 cells. (A) PGE2 levels and (B) interleukin (IL)-6 levels. The cytokine levels were determined using an enzyme-linked immunosorbent assay (ELISA). Absorbance was measured at $450 \mathrm{~nm}$ using a microplate reader. Significantly different from the control, ${ }^{\#} \mathrm{P}<0.05$; significantly different from the cells treated with LPS alone, ${ }^{*} \mathrm{P}<0.05$; significantly different from the cells treated with LPS alone, ${ }^{* *} \mathrm{P}<0.01$.

A
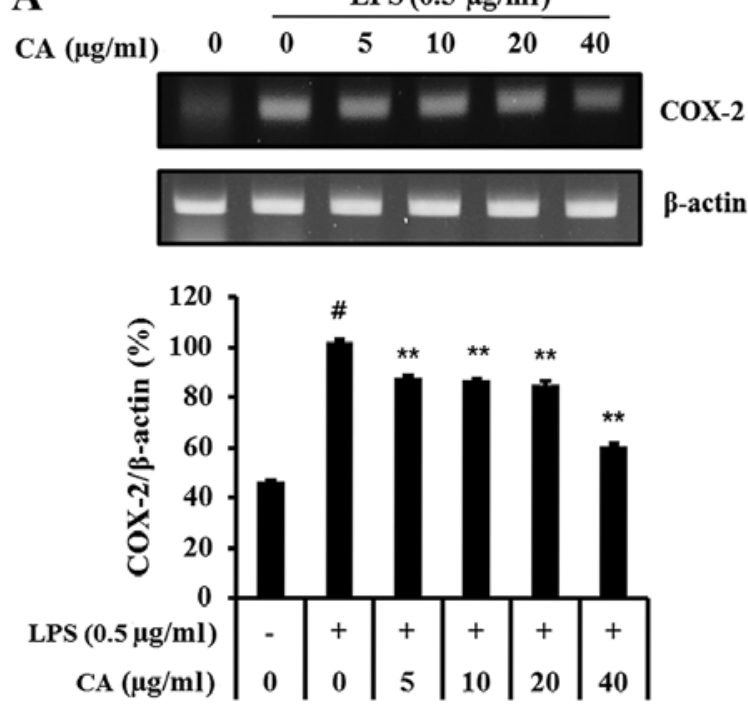

B
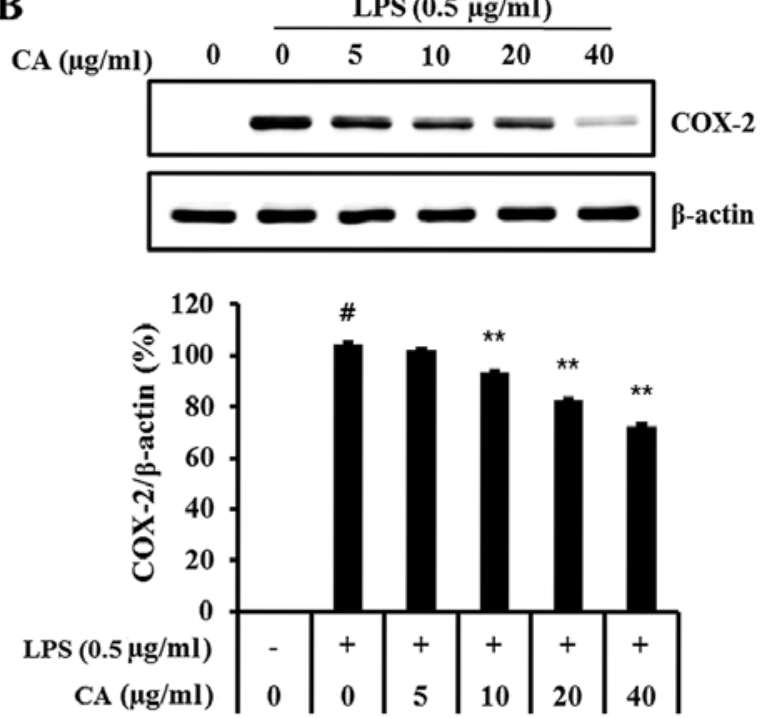

Figure 3. C. anisata (CA) reduces the expression of cyclooxygenase-2 (COX-2) in lipopolysaccharide (LPS)-stimulated RAW 264.7 cells. (A) mRNA expression of COX-2 determined by RT-qPCR using $\beta$-actin as the internal control. (B) Protein expression levels of COX-2 determined by western blot analysis using $\beta$-actin as the internal control. Significantly different from the control, ${ }^{\#} \mathrm{P}<0.05$; significantly different from the cells treated with LPS alone, ${ }^{* *} \mathrm{P}<0.01$. 


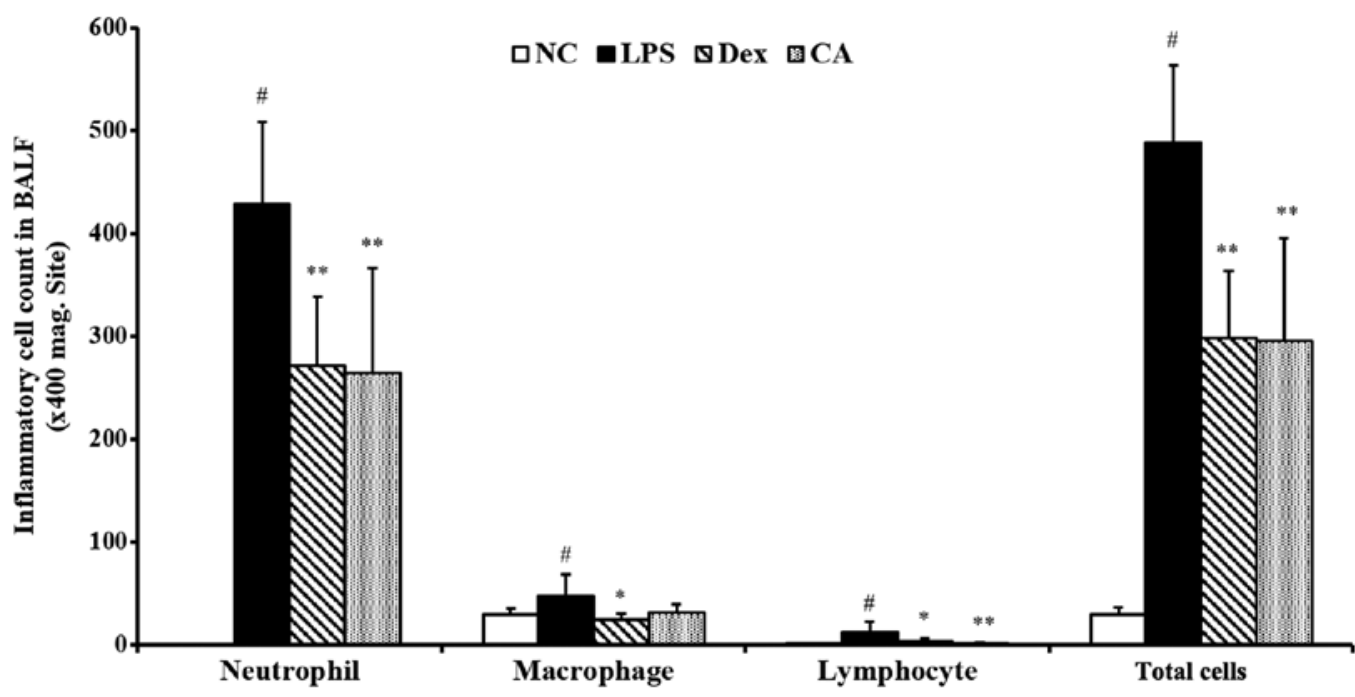

Figure 4. C. anisata (CA) suppresses the increased inflammatory cell counts in bronchoalveolar lavage fluid (BALF) induced by lipopolysaccharide (LPS) exposure. Cells were isolated by centrifugation and stained with Diff-Quik ${ }^{\circledast}$ staining reagent. The cell numbers were counted using a light microscope at $\mathrm{x} 400$ magnification. NC, normal control mice treated with PBS only; LPS, LPS intranasal (i.n.) instillation; Dex, Dexamethasone (oral gavage of $5 \mathrm{mg} / \mathrm{kg}$ ) + LPS i.n. instillation; CA, (oral gavage of $30 \mathrm{mg} / \mathrm{kg}$ ) + LPS i.n. instillation. The LPS-treated mice exhibited increased inflammatory cell counts in the BALF relative to the normal control groups. By contrast, the CA-treated mice exhibited reduced inflammatory cell counts (particularly neutrophil counts) in the BALF compared to the LPS-treated mice. Significantly different from the normal control group, ${ }^{*} \mathrm{P}<0.05$; significantly different from the LPS-treated mice group, ${ }^{*} \mathrm{P}<0.05$; significantly different from the LPS-treated mice group, ${ }^{* *} \mathrm{P}<0.01$.

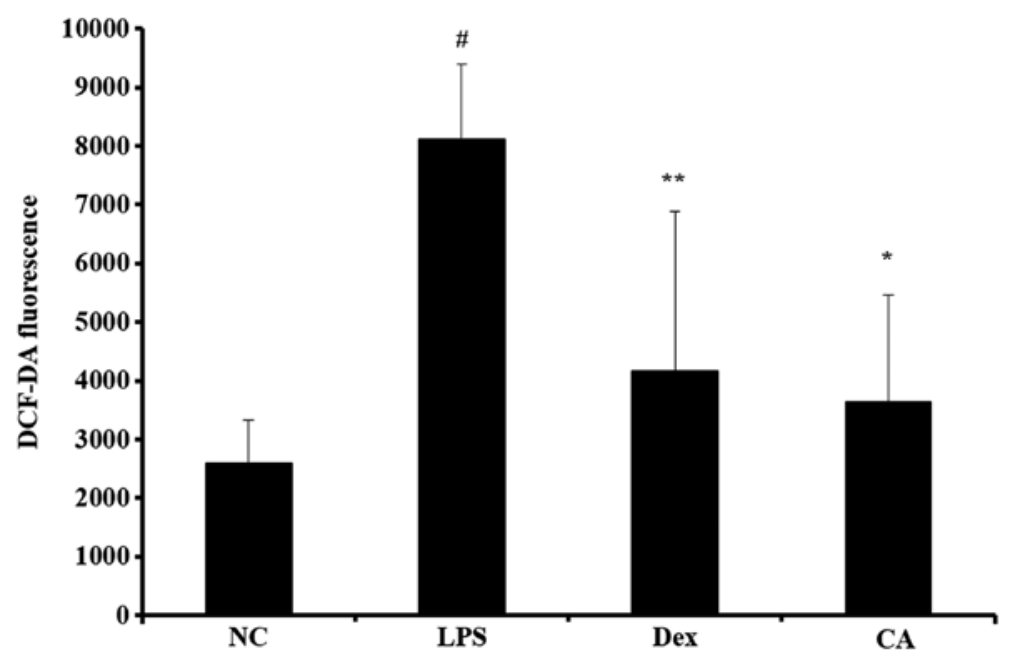

Figure 5. C. anisata (CA) reduces reactive oxygen species (ROS) production in BALF induced by lipopolysaccharide (LPS) exposure. The LPS-treated mice exhibited increased ROS production in the BALF compared with the normal control group. By contrast, the CA-treated mice exhibited reduced ROS production in the BALF compared with the LPS-treated mice. Significantly different from the normal control group, ${ }^{\text {}} \mathrm{P}<0.05$; significantly different from the LPS-treated mice group, ${ }^{*} \mathrm{P}<0.05$; significantly different from the LPS-treated mice group, ${ }^{* *} \mathrm{P}<0.01$.

number of total cells, neutrophils, macrophages and lymphocytes compared with the control group. However, BALF samples from the CA-treated mice exhibited a significantly decreased influx of total cells, neutrophils, macrophages and lymphocytes compared with the LPS-treated mice (Fig. 4). The reductions were similar to the results obtained in the dexamethasone-treated mice.

Effect of CA on ROS production in the BALF isolated from mice with LPS-induced ALI. ROS levels in the BALF were significantly increased in LPS-treated mice compared with the negative controls group (Fig. 5). By contrast, the CA-treated mice exhibited a significant decrease in ROS production compared with the LPS-treated mice. The reductions were similar to the results obtained for the dexamethasone-treated mice.
Effect of CA on pro-inflammatory cytokine production in the BALF isolated from mice with LPS-induced ALI. TNF- $\alpha$, IL- $1 \beta$ and IL- 6 levels in the BALF were significantly increased in LPS-treated mice compared with the negative control group (Fig. 6). By contrast, CA-treated mice exhibited a significant decrease in TNF- $\alpha$, IL-1 $\beta$ and IL- 6 levels compared with the LPS-treated mice. The reductions were similar to the results obtained in the dexamethasone-treated mice.

Effects of CA on the inflammatory response in the lung tissue of mice with LPS-induced ALI. To evaluate histological changes following LPS treatment of LPS-induced lung inflammation, the lung sections were subjected to H\&E staining. 


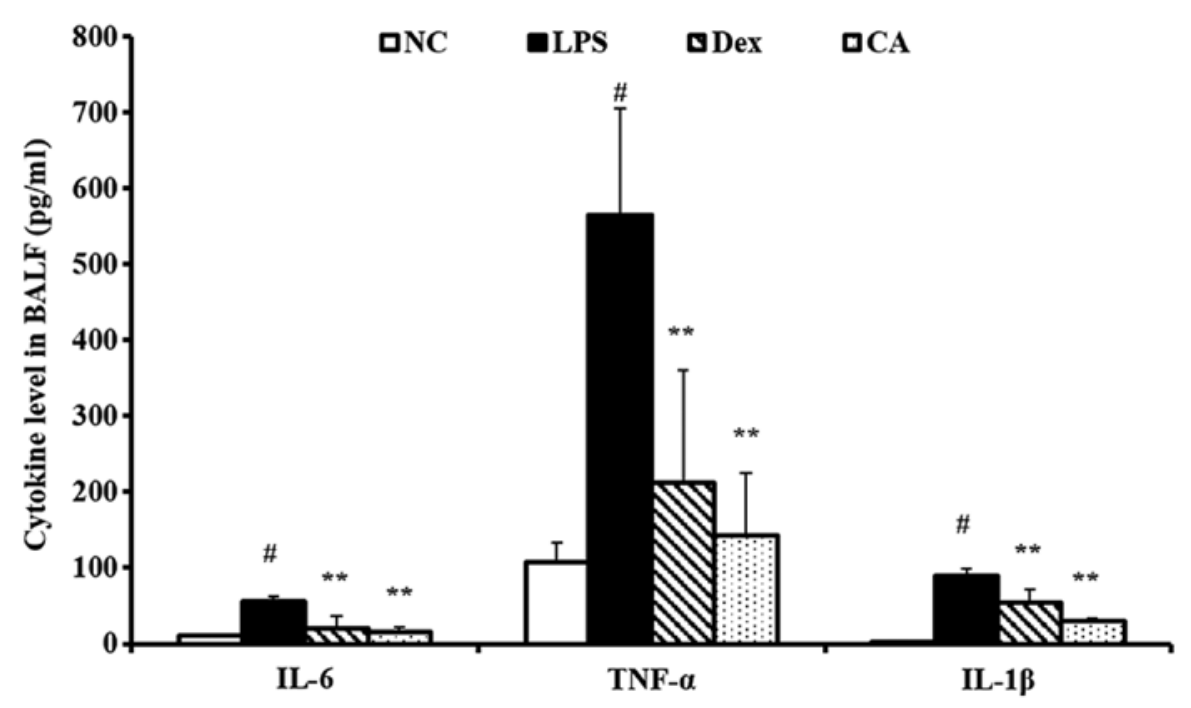

Figure 6. C. anisata (CA) reduces the levels of pro-inflammatory cytokine in the bronchoalveolar lavage fluid (BALF) induced by lipopolysaccharide (LPS) exposure. The LPS-treated mice exhibited increases in pro-inflammatory cytokines, including interleukin (IL)-6, tumor necrosis factor- $\alpha$ (TNF- $\alpha$ ), and IL-1 $\beta$ compared with the normal control group. However, the CA-treated mice exhibited marked reductions in pro-inflammatory cytokines compared with the LPS-treated mice. Significantly different from the normal control group, ${ }^{\prime \prime} \mathrm{P}<0.05$; significantly different from the LPS-treated mice group, ${ }^{* * *} \mathrm{P}<0.01$.
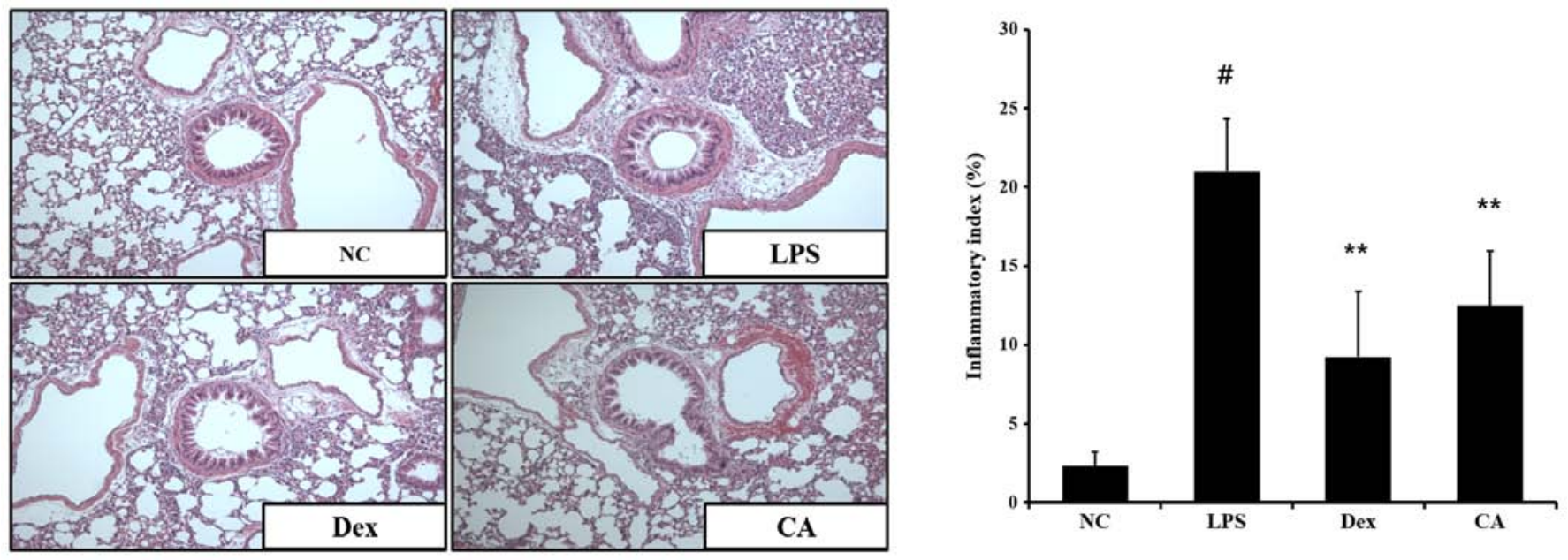

Figure 7. C. anisata (CA) attenuates inflammatory responses in lung tissue induced by lipopolysaccharide (LPS) exposure. A representative figure of peribronchial lesions and alveolar lesions in the lung tissue stained with H\&E solution. The LPS-treated mice exhibited airway inflammation. However, the CA-treated mice exhibited reduced airway inflammation compared with the LPS-treated mice. Significantly different from the normal control group, ${ }^{\text {"}} \mathrm{P}<0.05$; significantly different from the LPS-treated mice group, ${ }^{* *} \mathrm{P}<0.01$.

Significant pathological changes were observed in the lungs of LPS-treated mice including inflammatory cell infiltration, lung tissue damage, and alveolar wall thickening. However, fewer histopathological changes were observed in the lung tissues of CA-treated mice compared with the LPS-treated mice (Fig. 7). The reductions were similar to the results obtained in the dexamethasone-treated mice.

Effect of CA on protein expression of pro-inflammatory mediators in the lung tissue of mice with LPS-induced ALI. Mice with LPS-induced ALI exhibited increased I $\mathrm{B}$ and $\mathrm{NF}-\kappa \mathrm{B}$ phosphorylation in the lung tissue samples compared with the negative control group. However, there was signifi-

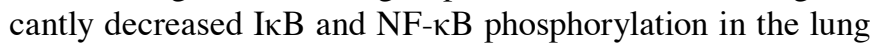

tissue of CA-treated mice compared with the LPS-treated mice (Fig. 8). The reductions were similar to the results obtained in the dexamethasone-treated mice.

\section{Discussion}

CA is a traditional medicine that is widely used for its reported antitumor and anti-inflammatory activities (19-25). The aim of the present study was to investigate the potential therapeutic effects of CA in a mouse model of LPS-induced ALI and in LPS-stimulated RAW 264.7 cells. In vitro, CA decreased NO production and pro-inflammatory cytokines, such as IL-6, as well as $\mathrm{PGE}_{2}$ in LPS-stimulated RAW 264.7 

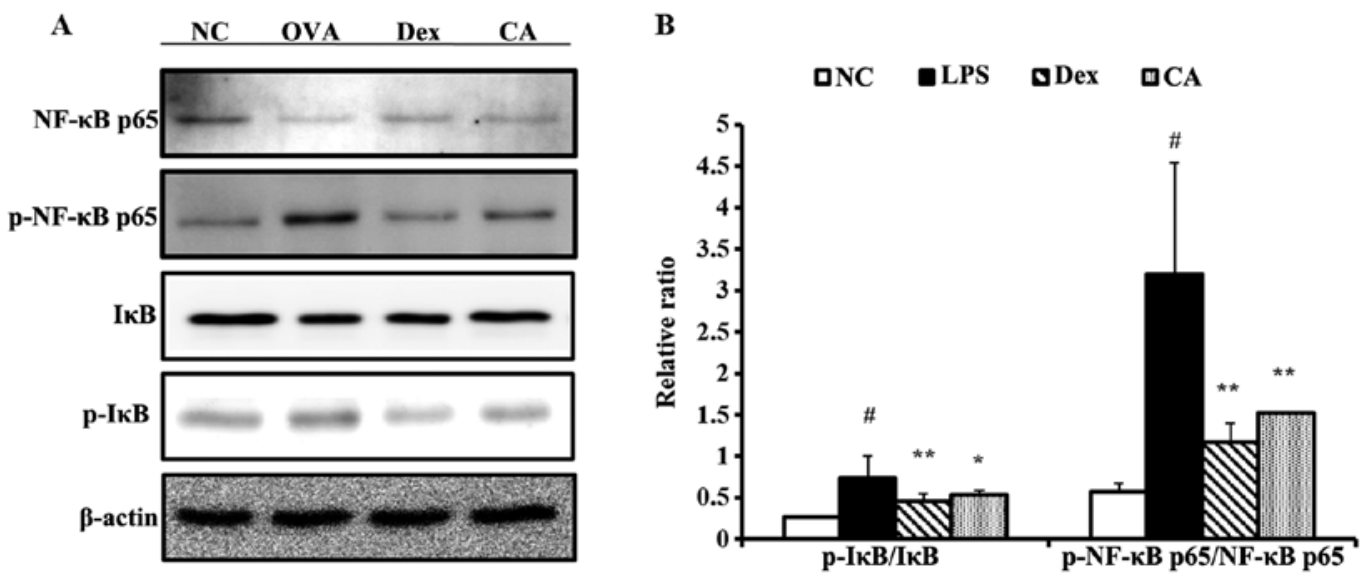

Figure 8. C. anisata (CA) reduces the phosphorylation of nuclear factor- $\kappa \mathrm{B}$ (NF- $\kappa \mathrm{B})$ in lung tissue induced by lipopolysaccharide (LPS) exposure. (A) Expression

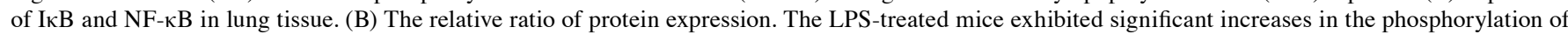
$\mathrm{NF}-\mathrm{\kappa B}$ compared to the normal control group. By contrast, the CA-treated mice exhibited marked reductions in the expression of these factors in lung tissue compared with the LPS-treated mice. Significantly different from the normal control group, ${ }^{\#} \mathrm{P}<0.05$; significantly different from the LPS-treated mice group, ${ }^{*} \mathrm{P}<0.05$; significantly different from the LPS-treated mice group, ${ }^{* *} \mathrm{P}<0.01$.

cells. CA also reduced the expression of pro-inflammatory mediators such as COX-2. In vivo, CA-treated mice had significantly reduced inflammatory cell counts in the BALF and suppressed pro-inflammatory cytokine levels, including TNF- $\alpha$, IL- 6 and IL- $1 \beta$, as well as decreased production of ROS in the BALF. CA effectively reduced airway inflammation in the lung tissue, in addition to decreasing $І \kappa B$ and NF- $\kappa B$ p65 phosphorylation, compared with the LPS-treated mice.

Previous studies have demonstrated that LPS stimulates alveolar macrophages and it is important in the development of ALI. Stimulated alveolar macrophages produce $\mathrm{NO}, \mathrm{PGE}_{2}$ and pro-inflammatory cytokines, such as TNF- $\alpha$, IL- 6 and IL-1 $\beta(11,12)$. These cytokines play critical roles in the inflammatory responses that are featured in ALI and contribute to the severity of the lung injury (26-28). TNF- $\alpha$, IL- 6 and IL-1 $\beta$ amplify the entire, or focal, inflammatory responses as well as the recruitment of neutrophils into the lung in ALI (29). TNF- $\alpha$, the earliest primary endogenous mediator of an inflammatory reaction, has been demonstrated to damage vascular endothelial cells and induce alveolar epithelial cells to produce other cell factors, such as IL-6 $(30,31)$. TNF- $\alpha$ also elevates levels of intracellular ROS, which is an important factors in the pathogenesis of ALI. IL-6 is a product of TNF- $\alpha$-induced epithelial cells and in ALI it is one of the most common inflammatory cytokines and it is also a significant predictor of morbidity and mortality in patients with ARDS (29). Moreover, IL-1 $\beta$ inhibits fluid transportations across the distal lung epithelium to cause surfactant disorders and to increase protein permeability across the alveolarcapillary barrier (32). In the present study, we determined that CA decreased TNF- $\alpha$, IL6, and IL- $1 \beta$ production compared with LPS-treatment alone. The inhibition of pro-inflammatory cytokine production was in accordance with the effects of CA on LPS-induced histological changes and ROS production. CA significantly suppressed the LPS-induced increase in ROS production in the BALF. CA administration also attenuated the extensive LPS-induced inflammatory responses in the lung tissues. These finding indicate that CA has protective effects on LPS instillation-induced ALI.

Previous studies $(33,34)$ have indicated that pro-inflammatory cytokine production is modulated by the NF- $\mathrm{KB}$ signaling pathway. NF- $\mathrm{KB}$ is an important nuclear transcription factor that is responsible for inflammation, and it plays a critical role in regulating immune and inflammatory responses. In normal conditions, heterodimers of NF- $\mathrm{KB}$ complexes, which are mostly p50/p65, are present as an inactive cytoplasmic form with IкB in the cytoplasm $(35,37)$. However, LPS stimulation is known to cause $\mathrm{I} \kappa \mathrm{B}$ phosphorylation by the $\mathrm{I} \kappa \mathrm{B}$ kinase complex, which results in degradation via the ubiquitinproteasome pathway. IкB degradation leads to NF- $\kappa B$ dimer phosphorylation and translocation to the nucleus where it activates the transcription of specific target genes, including TNF- $\alpha$, IL-1 $\beta$, IL-6, COX-2 and PGE $_{2}$ (15-18). In patients with ALI, NF- $\mathrm{kB}$ activation increases pro-inflammatory cytokines, which promotes inflammatory responses and neutrophil recruitment into the lung (37). COX-2 expression, has also been demonstrated to increase inflammatory cells and induce the expression of prostaglandins, which aggravate inflammatory responses (38). In the present study, we investigated whether the anti-inflammatory activity of CA was exerted via the NF- $\kappa B$ signaling pathway, in the lung tissue of mice with ALI. In vivo, CA demonstrated a significant reduction in NF- $\kappa \mathrm{B}$ phosphorylation and $\mathrm{I} \kappa \mathrm{B}$ degradation. In vitro, $\mathrm{CA}$ markedly decreased COX-2 expression and reduced $\mathrm{PGE}_{2}$ production in LPS-stimulated RAW 264.7 cells. Thus, CA possesses anti-inflammatory activity in mice with ALI and LPS-stimulated RAW 264.7 cells. These effects are associated with downregulation of the NF- $\mathrm{KB}$ signaling pathway.

In conclusion, $\mathrm{CA}$ demonstrated effective suppression of the pro-inflammatory cytokines, ROS, $\mathrm{NO}$ and $\mathrm{PGE}_{2}$ in LPS-stimulated RAW 264.7 cells and in mice with LPS-induced ALI. These effects were closely associated with the suppression of NF- $\kappa \mathrm{B}$ phosphorylation. Thus, CA is a potential candidate for development as an adjunctive treatment forof inflammatory disorders, such as ALI. 


\section{Acknowledgements}

This study was supported by the grants from the Ministry of Science, ICT and Future Planning (FGC1011534) and the KRBB Research Initiative Program (KGM1221622) of the Republic of Korea.

\section{References}

1. Basu RK, Chawla LS, Wheeler DS and Goldstein SL: Renal angina: an emerging paradigm to identify children at risk for acute kidney injury. Pediatr Nephrol 27: 1067-1078, 2012.

2. Atabai K and Matthay MA: The pulmonary physician in critical care. 5: Acute lung injury and the acute respiratory distress syndrome: definitions and epidemiology. Thorax 57: 452-458, 2002.

3. Raghavendran K and Napolitano LM: Definition of ALI/ARDS. Crit Care Clin 27: 429-437, 2011.

4. Chignard M and Balloy V: Neutrophil recruitment and increased permeability during acute lung injury induced by lipopolysaccharide. Am J Physiol Lung Cell Mol Physiol 279: L1083-L1090, 2000.

5. Shang Y, Li X, Prasad PV, Xu S, Yao S, Liu D, Yuan S and Feng D: Erythropoietin attenuates lung injury in lipopolysaccharide treated rats. J Surg Res 155: 104-110, 2009.

6. Diaz JV, Brower R, Calfee CS and Matthay MA: Therapeutic strategies for severe acute lung injury. Crit Care Med 38: $1644-1650,2010$

7. Imai Y, Kuba K, Neely GG, Yaghubian-Malhami R, Perkmann T, van Loo G, Ermolaeva M, Veldhuizen R, Leung YH, Wang $\mathrm{H}$, et al: Identification of oxidative stress and Toll-like receptor 4 signaling as a key pathway of acute lung injury. Cell 133: 235-249, 2008.

8. Zambon M and Vincent JL: Mortality rates for patients with acute lung injury/ARDS have decreased over time. Chest 133 $1120-1127,2008$

9. Kitamura Y, Hashimoto S, Mizuta N, Kobayashi A, Kooguchi K, Fujiwara I and Nakajima H: Fas/FasL-dependent apoptosis of alveolar cells after lipopolysaccharide-induced lung injury in mice. Am J Respir Crit Care Med 163: 762-769, 2001.

10. Abraham E, Nick JA, Azam T, Kim SH, Mira JP, Svetkauskaite D He Q, Zamora M, Murphy J, Park JS, et al: Peripheral blood neutrophil activation patterns are associated with pulmonary inflammatory responses to lipopolysaccharide in humans. J Immunol 176: 7753-7760, 2006.

11. Bhatia M and Moochhala S: Role of inflammatory mediators in the pathophysiology of acute respiratory distress syndrome. J Pathol 202: 145-156, 2004.

12. Bouwmeester T, Bauch A, Ruffner H, Angrand PO, Bergamini G, Croughton K, Cruciat C, Eberhard D, Gagneur J, Ghidelli S, et al: A physical and functional map of the human TNF-alpha/NF-kappa B signal transduction pathway. Nat Cell Biol 6: 97-105, 2004.

13. Auron PE: The interleukin 1 receptor: Ligand interactions and signal transduction. Cytokine Growth Factor Rev 9: 221-237, 1998.

14. Creager MA, Luscher TF, Cosentino F and Beckman JA: Diabetes and vascular disease: pathophysiology, clinical consequences, and medical therapy: Part I. Circulation 108: 1527-1532, 2003.

15. Kagan JC and Medzhitov R: Phosphoinositide-mediated adaptor recruitment controls Toll-like receptor signaling. Cell 125: 943-955, 2006

16. Wilson SJ, Leone BA, Anderson D, Manning A and Holgate ST: Immunohistochemical analysis of the activation of NF-kappaB and expression of associated cytokines and adhesion molecules in human models of allergic inflammation. J Pathol 189: 265-272, 1999.

17. Richmond A: NF-kappa B, chemokine gene transcription and tumour growth. Nat Rev Immunol 2: 664-674, 2002.

18. Karin M and Ben-Neriah Y: Phosphorylation meets ubiquitination: The control of NF-[kappa]B activity. Annu Rev Immunol 18: 621-663, 2000.
19. Senthikumar A and Venkatesalu V: Phytochemical analysis and antibacterial activity of essential oil of Clausena anisata (Wild). Hook. F. ex Benth. Int J Intergrat Biol 5: 116-120, 2009.

20. Ajibesin KK, Ekpo BA, Bala DN, Essien EE and Adesanya SA: Ethnobotanical survey of Akwa Ibom State of Nigeria. J Ethnopharmacol 115: 387-408, 2008.

21. Hutchings A, Scott AH, Lewis G and Cunningham AB: Zulu Medicinal Plants - An Inventory. 1st edition. University of Natal Press, Pietermaritzburg, 1996.

22. Lakshmi V, Prakash D, Raj K, Kapil RS and Popli SP: Monoterpenoid furanocoumarin lactones from Clausena anisata. Phytochemistry 23: 2629-2631, 1984.

23. Adesina SK and Adewunmi CO: Molluscicidal agents from the root of Clausena anisata. Fitoterapia 56: 289-292, 1985.

24. Makanju OO: Behavioral and anticonvulsant effects of an aqueous extract from the roots of Clausena anisata. Int J Crude Drug Res 21: 29-32, 1983

25. Watt JM and Breyer Brandwijk MG: The Medicinal and Poisonous Plants of Southern and Eastern Africa. 2nd edition. E. and S. Livingstone, London, 1962.

26. Ganter MT, Roux J, Miyazawa B, Howard M, Frank JA, Su G, Sheppard D, Violette SM, Weinreb PH, Horan GS, et al: Interleukin-1beta causes acute lung injury via alphavbeta5 and alphavbeta6 integrin-dependent mechanisms. Circ Res 102: 804-812, 2008

27. Kolb M, Margetts PJ, Anthony DC, Pitossi F and Gauldie J: Transient expression of IL-1 $\beta$ induces acute lung injury and chronic repair leading to pulmonary fibrosis. J Clin Invest 107: 1529-1536, 2001

28. Giebelen IA, van Westerloo DJ, LaRosa GJ, de Vos AF and van der Poll T: Local stimulation of alpha7 cholinergic receptors inhibits LPS-induced TNF-alpha release in the mouse lung. Shock 28: 700-703, 2007

29. Matthay MA and Zimmerman GA: Acute lung injury and the acute respiratory distress syndrome: Four decades of inquiry into pathogenesis and rational management. Am J Respir Cell Mol Biol 33: 319-327, 2005.

30. Scheller J, Chalaris A, Schmidt-Arras D and Rose-John S: The pro- and anti-inflammatory properties of the cytokine interleukin-6. Biochim Biophys Acta 1813: 878-888, 2011.

31. Mukhopadhyay S, Hoidal JR and Mukherjee TK: Role of TNFalpha in pulmonary pathophysiology. Respir Res 7: 125, 2006.

32. Yang HZ, Wang JP, Mi S, Liu HZ, Cui B, Yan HM, Yan J, Li Z, Liu H, Hua F, et al: TLR4 activity is required in the resolution of pulmonary inflammation and fibrosis after acute and chronic lung injury. Am J Pathol 180: 275-292, 2012.

33. Ghosh S and Hayden MS: New regulators of NF-kappaB in inflammation. Nat Rev Immunol 8: 837-848, 2008.

34. Fu Y,Liu B,Zhang N, Liu Z, Liang D, Li F, Cao Y, Feng X, Zhang X and Yang Z: Magnolol inhibits lipopolysaccharide-induced inflammatory response by interfering with TLR4 mediated $\mathrm{NF}-\kappa \mathrm{B}$ and MAPKs signaling pathways. J Ethnopharmacol 145: 193-199, 2013.

35. Moine P, McIntyre R, Schwartz MD, Kaneko D, Shenkar R, Le Tulzo Y, Moore EE and Abraham E: NF-kappaB regulatory mechanisms in alveolar macrophages from patients with acute respiratory distress syndrome. Shock 13: 85-91, 2000.

36. Goodman RB, Pugin J, Lee JS and Matthay MA: Cytokinemediated inflammation in acute lung injury. Cytokine Growth Factor Rev 14: 523-535, 2003

37. Kuo MY, Liao MF, Chen FL, Li YC, Yang ML, Lin RH and Kuan YH: Luteolin attenuates the pulmonary inflammatory response involves abilities of antioxidation and inhibition of MAPK and NFKB pathways in mice with endotoxin-induced acute lung injury. Food Chem Toxicol 49: 2660-2666, 2011.

38. Redington AE, Meng QH, Springall DR, Evans TJ, Créminon C, Maclouf J, Holgate ST, Howarth PH and Polak JM: Increased expression of inducible nitric oxide synthase and cyclooxygenase- 2 in the airway epithelium of asthmatic subjects and regulation by corticosteroid treatment. Thorax 56: 351-357, 2001. 